https://helda.helsinki.fi

\title{
Employer views on upper-secondary vocational graduate competences
}

\section{Löfgren, Sami}

2020

Löfgren , S , llomäki , L \& Toom , A 2020 , ' Employer views on upper-secondary vocational graduate competences ' , Journal of Vocational Education and Training , vol. 72 , no. 3 , pp. 435-460 . https://doi.org/10.1080/13636820.2019.1635633

http://hdl.handle.net/10138/326221

https://doi.org/10.1080/13636820.2019.1635633

acceptedVersion

Downloaded from Helda, University of Helsinki institutional repository.

This is an electronic reprint of the original article.

This reprint may differ from the original in pagination and typographic detail.

Please cite the original version. 


\title{
Employer Views on Upper-Secondary Vocational Graduate Competences
}

\section{Journal of Vocational Education \& Training}

Sami Löfgren ${ }^{\mathrm{a} *}$, Liisa Ilomäki ${ }^{\mathrm{b}}$, and Auli Toom ${ }^{\mathrm{c}}$

${ }^{a}$ Faculty of Educational Sciences, University of Helsinki, Finland; SEDUCE Doctoral

Programme (corresponding author); ${ }^{b}$ Technology in Education Research Group, Faculty of

Educational Sciences, University of Helsinki, Finland; ${ }^{c}$ Centre for University Teaching and

Learning, Faculty of Educational Sciences, University of Helsinki, Finland

\author{
${ }^{a *}$ P.O. BOX 9, FI-00014 University of Helsinki, Finland \\ Tel. +358503772078 \\ sami.lofgren@helsinki.fi \\ LinkedIn: https://www.linkedin.com/pub/sami-löfgren/13/137/a29 \\ ORCiD: http://orcid.org/0000-0001-6630-2691 \\ ${ }^{b}$ P.O. BOX 9 FI-00014 University of Helsinki, Finland \\ Tel. +358505114376 \\ liisa.ilomaki@helsinki.fi \\ ORCiD: http://orcid.org/0000-0002-5429-7853 \\ ${ }^{c}$ P.O. BOX 9, FI-00014 University of Helsinki, Finland \\ Tel. +358504154852 \\ auli.toom@helsinki.fi \\ ORCiD: http://orcid.org/0000-0002-3261-3376
}

\section{Biographical notes}

Sami Löfgren, EdM, is a doctoral candidate in the doctoral programme of School, Education, Society and Culture (SEDUCE) at Faculty of Educational Sciences, University of Helsinki. His research interests lie in vocational education and training, working life competences and transition from school to work.

Liisa Ilomäki, EdD, is a researcher at the Technology in Education Research Group, University of Helsinki, Finland. Her current research interests include the knowledge work competencies and pedagogical practices, the effects of digital technology in learning and teaching and school in general. Her school-related research interest is in promoting the use of new digital technology for innovative pedagogical practices.

Auli Toom, PhD, Professor of Higher Education, is the Director of the Centre for University Teaching and Learning at Faculty of Educational Sciences, University of Helsinki. She is also Visiting Professor at the Institute of Education, University of Tartu, Estonia. Her research interests include student learning of knowledge work competencies, pedagogies supporting learning as well as teacher knowing and teacher education. 


\section{Employer Views on Upper-Secondary Vocational Graduate Competences}

To become employed, upper-secondary vocational graduates need adequate competences that correspond with the needs of working life, particularly with the expectations of their potential employers. However, research on the necessary competences of upper-secondary vocational education and training (VET) students is limited. This study examined what competences technical-trade employers expect of initial vocational education (IVET) graduates, which competences stand out in recruitment and what kind of experiences the employers had on the competences of their recent apprentices and novice employees. The study was conducted in the metropolitan area of Southern Finland. Ten representatives of employers offering apprenticeships for technical-trade IVET students were interviewed. The data consisted of interview transcriptions that were analysed using qualitative content analysis. The findings indicate that graduates' motivational, attitudinal and social competences contribute to businesses' employment decisions but only when the graduates have shown potential for vocational development as well. The findings further suggest that when graduating, young people possess adequate competences to a varying degree and some of them are insufficiently prepared.

Keywords: vocational education \& training; competence; VET and the labour market; policy issues; learning in life \& work transitions

\section{Introduction}

Rapid and constant changes characterize the modern workplace. Novel scientific and technological advancements emerge and as a part of global knowledge exchange they get internationally spread at a rapid pace (Evers and Van der Heijden 2016; Gekara and Snell 2018). To survive in the global market, organizations need to develop and keep up with the new knowledge requirements and, as a consequence, the job tasks conducted in the organizations get ever-changing, non-standardized and partly replaced by the new technology (as suggested by European Council and European Commission [2010]; Evers and Van der Heijden [2016]). To enter the job market, job seekers must acquire more complex 
qualifications; still, qualifications become obsolete relatively quickly and do not guarantee one’s productivity and employability for good (Evers and Van der Heijden 2016; Gekara and Snell 2018). In such a situation, job seekers and also employees should be ready to adapt and act (European Council and European Commission 2010; Gekara and Snell 2018). Allegedly, the best way is to acquire competences, which refer to integrated sets of transferable knowledge, skills and attitudes (e.g., Blömeke, Gustafsson, and Shavelson 2015; Nägele and Stalder 2016; OECD 2016). They derive relatively directly from real-life situations and are highly valued by employers (Nägele and Stalder 2016; Tymon 2013).

Competence demands concern educational organizations and students as well (Gekara and Snell 2018; Nägele and Stalder 2016). In fact, upper-secondary initial vocational educational and training (IVET) aims to develop competent behaviour in professional practice; thus, students are assessed not only regarding their understanding of curricular contents, theories and concepts but also on how they apply their knowledge in real-life professional tasks, often by hand (Baartman and de Bruijn 2011; Nägele and Stalder 2016). Learning by doing, students should also develop a vocational identity and gradually become members of their professional communities (e.g., Baartman and de Bruijn 2011; Ferm et al. 2018; Nägele \& Stalder 2016). However, when school leavers are trying to get employed for the first time, they cannot distinguish themselves with extensive work experience; thus, they have to convince the recruiting employer with their transferable competences (Nägele and Stalder 2016), preferably during the on-the-job learning periods (Pylväs, Nokelainen, and Rintala 2018). What these include, is a matter of constant debate and always a 'trade-off' between different stakeholders (Mulder 2016).

The discussion on competence demands within vocational education and training has been led by institutional stakeholders, for example industry organizations, trade 
unions and governmental institutions (Billett 2014, Mulder 2016). The views of actual practitioners have been scarcely studied (Billett 2014). Moreover, as competence demands in the modern working life progressively link to specific job tasks (Nägele and Stalder, 2016), there is a risk that the above-mentioned institutional viewpoints dismiss the breadth of job contexts. To advance the discussion on competence demands, Nägele and Stalder (2016) suggest that job tasks and competence demands should be scrutinized between and within different economic sectors and occupations. This discussion should involve all relevant stakeholders, for instance employers, teachers and students (Mulder 2016; Nylund et al. 2018). Earlier research within upper-secondary and higher education also suggests that this discussion should be started from employer views because student employability is likely to improve when there is a fit between employers' demands and students' competences (Jackson 2015; Nägele and Stalder 2016; Teijeiro, Rungo, and Freire 2013). Thus, we consider practitioner-level technical-trade employer views as a starting point for the discussion and examine in this study what competences they expect of upper-secondary IVET graduates.

This paper has the following structure. In the next section, we present the theoretical background of our study. First, we examine the definition of the concept of competence (e.g. Blömeke, Gustafsson, and Shavelson 2015; Nägele and Stalder 2016; Toom 2012) and point out that it may have different contents depending on the focused context and on the stakeholders concerned (e.g. Nägele and Stalder 2016; Pylväs, Nokelainen, and Rintala 2018). Second, we outline these contents within IVET especially from the employers' point of view (e.g. Jackson 2015; Kantane et al. 2015; Pylväs, Nokelainen, and Rintala 2018; McMurray et al. 2016). We emphasize that competences promote not only individual work performance but also one's position as a fellow employee and that is why we also refer to the theory of Organizational Citizenship Behaviours (OCBs; Bolino, Harvey, and Bachrach 
2012). After the theoretical background, we describe the qualitative methodological approach applied in this study. Then, we report our results in three sections that address what competences employers expect of technical-trade IVET graduates, how important these expectations are in recruitment situations and what kind of experiences the employers have of technical-trade IVET graduates. Last, we discuss our results in light of the previous literature and make the conclusion that technical-trade IVET graduates are crucial for the continuity of their vocational trades but are very heterogenous in terms of their competences.

\section{Theoretical background}

\section{Working life competences}

The overall performance of an employee is shown as an interplay of a job task and his or her expertise (Blömeke, Gustafsson, and Shavelson 2015; Tynjälä 2008). In general, expertise includes three highly integrated elements: 1) theoretical knowledge which is labelled as formal or declarative; 2) practical (or procedural) knowledge which refers to skilled, intuitive behaviour in real-life work situations; and 3) self-regulative knowledge which is essential to guide (i.e., metacognition) and reflect one’s actions at work (Tynjälä 2008).

Further, expertise can be seen through different domains, commonly referred as competences. They consist of integrated pieces of knowledge, skills and attitudes that enable an individual to act successfully in various real-life, ill-defined situations (Blömeke, Gustafsson, and Shavelson 2015; Ilomäki et al. 2016; Toom 2012). On the one hand, there is domain-specific competence which is essential to execute a certain job task (Blömeke, Gustafsson, and Shavelson 2015; Gekara and Snell 2018; Tymon 2013) such as the ability to weld or paint a car. However, such skills might have only limited applicability in other professions (Gekara and Snell 2018). 
On the other hand, there are various domain-general competences that may not be enough to execute certain job tasks as such but which are broadly generalizable, improve the adaptation in various transitions of work and everyday life and help to retain one's employability through a career (OECD 2016, 120; Jackson 2015; Tymon 2013). International political and educational organizations (such as European Union and OECD) have attempted to define and select the most important domain-general competences for the citizens of modern Western societies (Nägele and Stalder 2016). For instance, there are requirements of literacy, numeracy, digital and problem-solving competence as well as social, citizenship and learning skills that are expected from employees regardless of their profession (Nägele and Stalder 2016; see also European Council and European Commission 2010; OECD 2016).

Despite some agreement upon the nature of the concept of competence, its precise definition and content remain ambiguous (Nägele and Stalder 2016; Blömeke, Gustafsson, and Shavelson 2015; Toom 2012). On one hand, the debate on definition has been twofold. Competences have been defined through their outcomes as an individual's capability to pursue high performance, or through their antecedents as personal characteristics or traits triggering this performance (Blömeke, Gustafsson, and Shavelson 2015). Such dichotomy is unwarranted as both viewpoints can be seen as a continuum serving each other (Blömeke, Gustafsson, and Shavelson 2015). Moreover, Evers and Van der Heijden (2016) argue that the concepts of competence and expertise may also be mixed up as they both are linked to one's ability to do something in a skillful way. However, a distinction could be made based on whether competences are considered static or dynamically evolving. According to van Tartwijk, Zwart, and Wubbels (2017), competences require continuous and diligent, self-regulated learning (i.e. deliberate practice) to enable one’s adaptation to new and on 22/06/2019, available online: http://www.tandfonline.com/10.1080/13636820.2019.1635633 
unknown situations and only then they might be perceived as 'expertise', representing their highest level.

On the other hand, different stakeholders have various nuanced views on the content of competences (Nägele and Stalder [2016]; Tymon [2013]; see also Ilomäki et al. [2016] about digital competence). Therefore, there should be an ongoing dialogue on competence needs between different stakeholders, such as educators, students and employers (Mulder 2016; Jackson 2015). Generally speaking, in the case of school leavers such as IVET graduates, domain-general competences (for example social competence, motivation, attitudes) have been argued to outweigh domain-specific competence as novices cannot outperform their older colleagues in substance knowledge and work performance due to their limited work experience (Nägele and Stalder 2016; Pylväs, Nokelainen, and Rintala 2018). In consequence, although possessing some initial domain-specific competence, it is reasonable to expect that IVET graduates distinguish themselves in domain-general competences in recruitment situations (Nägele and Stalder 2016). In the following, we present some general employer competence expectations. Due to the limited research within upper-secondary vocational education and training (VET; Billett 2014), we also refer to studies within tertiary education when necessary.

\section{IVET students' competences relevant for working life}

The development of students' domain-specific competence is the crux of IVET and what employers also anticipate (Gekara and Snell 2018; Nägele and Stalder 2016; Pylväs, Nokelainen, and Rintala 2018). These anticipations may be very detailed and context-related; therefore, their transferability should be considered carefully (Gekara and Snell 2018). However, to develop domain-specific competence, incoming IVET students should have a 
certain technological competence, including knowing technological concepts and principles essential to problem solving (Autio 2011). They should also have such psychomotor skills as coordination and dexterity to use craft tools correctly and have positive attitudes towards learning, practising and using technology, which may be shown by having technology-related hobbies (Autio 2011; Baartman and de Bruijn 2011).

In contrast, when recruiting graduates, employers value quite similar domaingeneral competences and favour these over domain-specific competence (Teijeiro et al. 2013; McMurray et al. 2016). According to earlier research within upper-secondary vocational and tertiary education, first, employers value motivated and vigorous graduates (Kantane et al. 2015; Pylväs, Nokelainen, and Rintala 2018; Teijeiro et al. 2013). Second, their future employees should interact with others in an appropriate, comprehensible and respectful way, for instance, when seeking for a job or serving customers (Kantane et al. 2015; McMurray et al. 2016; Tynjälä et al. 2016). Third, as competence demands constantly evolve so should everyone also be able and willing to learn and develop (Kantane et al. 2015; Teijeiro et al. 2013).

Furthermore, employers value graduates’ work-related attitudes (e.g. Jackson 2015; Kantane et al. 2015; Pylväs, Nokelainen, and Rintala 2018; McMurray et al. 2016). They expect that graduates possess as positive work-related attitudes as possible already when recruited because attitudes are changing slowly, and therefore it is difficult to alter attitudes through further training (Kantane et al. 2015). Attitudes can emerge both as reactive habits such as helping others, taking care of the job environment and one's own physical health, being flexible with job tasks and timetables and as proactive behaviour such as taking initiative (Baartman and de Bruijn 2011; Bolino, Harvey, and Bachrach 2012). 
The above-mentioned competences are not an exhaustive inventory of IVET graduate competence requirements but give an overview of general employer expectations. Further, Blömeke, Gustafsson and Shavelson (2015) argue that such a trait-based listing should always be perceived with the pursued performance as a continuum. Accordingly, we argue that competences can be seen to serve both individual and collective purposes. They are required to do one's job tasks but also a means to access a professional community and to get and keep a job (Ferm et al. 2018). For example, by helping others, individuals not only carry out their job tasks but also show positive attitudes. They relieve each other's burdens, create trust; thereby, they improve social cohesion at the workplace and their own membership in it (Bolino, Harvey, and Bachrach 2012; Pylväs, Nokelainen, and Rintala 2018). From the employers' standpoint, attitudes reflect employees' pro-company orientation that may improve an organization's performance and thus promote their employability (Bolino, Harvey, and Bachrach 2012). In fact, employees' attitudes have been also called as Organizational Citizenship Behaviours (OCBs) when referring to their positive contributions to the organizations' cohesion and performance (Bolino, Harvey, and Bachrach 2012). In conclusion, in our study we examine IVET graduate competences from the employers' viewpoint and perceive them as a means to act and develop as a professional, to acquire a membership in a professional community, and to get employed.

\section{The aim of this study}

This study aims to deepen the understanding on employer competence expectations from IVET graduates in technical trades. We want to discover which domain-general competences employers consider crucial for the start of students' careers and how well the IVET graduates master these. The following research questions are addressed: 
(1) What are the employers' expectations about the desirable competences possessed by upper-secondary vocational education graduates and how do the employers argue for these?

(2) How important are these competence expectations in graduate recruitment situations and how do the employers argue for their opinions?

(3) What kind of experiences do the employers have about young employees recently graduated from the upper-secondary IVET?

\section{Method}

\section{Context}

In Finland, most vocational education and training is offered and funded by municipalities, joint municipal authorities or the state (Cedefop ReferNet Finland 2016). All education providers including private institutions must be authorised by the Ministry of Education and follow VET curricula defined in the National Qualifications Framework (Cedefop ReferNet Finland 2016). IVET begins after 9-year-long compulsory school, lasts approximately 3 years and covers 180 competence points of which 30 points (corresponding a half study year) have to be earned in on-the-job learning as an apprentice (Cedefop ReferNet Finland 2016). However, despite the apprenticeship periods the Finnish IVET education is rather schoolbased as education providers are obliged to supervise that vocational curricula are followed also in apprenticeships and students have a close contact to their school also during their apprenticeships (Cedefop ReferNet Finland 2016; Pylväs, Nokelainen, and Rintala 2018).

In 1990s, competence-based education was introduced and gradually implemented to Finnish IVET (Nylund et al. 2018). From 2015 to 2018, the Finnish IVET went through its latest legislative reform (Cedefop ReferNet 2016; Pylväs, Nokelainen, and 
Rintala 2018). The aim of the reform was to improve the reactivity of IVET system to the changing competence demands of working life and enhance vocational graduates' employability (Cedefop ReferNet 2016; Nylund et al. 2018). These enhancements are pursued by tightening the collaboration between the education providers and the working life, providing on-the-job learning possibilities and task-specific skills and promoting individual learning paths (Cedefop ReferNet 2016; Nylund et al. 2018; Pylväs, Nokelainen, and Rintala 2018).

In this study, a large-size southern Finnish VET provider cooperated as a partner: annually, approximately 10000 students take a three-year-long upper-secondary vocational qualification in some 50 study programmes. They all attend apprenticeships in local organizations during their studies (at least 30 competence points of the total 180). Due to the high number of students and study programmes, first, this study was limited to the vocational fields of technology, transport and natural sciences. This decision had to be made to keep the size of research context manageable and coherent. Second, within these fields the study was further limited to four study programmes: metalwork and machinery, building maintenance technology, vehicle technology, and electrical engineering and automation technology. These were chosen because of all technical study programmes these had sent the most students to apprenticeships to local firms. Approximately 600 students attend these four study programmes annually.

\section{Participants}

The participants of this study ( $\mathrm{N}=10$, all male, age: 37-62, mean: 47.9 years) represented local stakeholder employers and were chosen in assistance of the VET provider. The selection criteria were as follows: 1) They represented employers in the four above-mentioned study 
programmes; 2) their organizations had received several apprentices during the preceding two years (2016-2017); 3) they personally had supervised apprentices (ranging from 2 to 21 apprentices between years 2016-2017) and 4) they volunteered for the study. Besides their voluntariness, no incentives were offered for participants and they were asked for a written consent. Consequently, ten participants were chosen. Two of them represented metalwork and machinery, two represented building maintenance technology, three represented vehicle technology and three represented electrical engineering and automation technology. The participants differed from each other, firstly, in terms of their education. Six of them had a three-year tertiary polytechnic education, e.g., electrical engineer. Two of them had taken a two-year tertiary technical education, e.g., technician engineer. Two of the participants had an upper-secondary vocational qualification as their highest education. Secondly, the participants had varying job experience from their industry, spanning from 15 to 38 years (mean: 27.6 years). Thirdly, four of them acted as both a partner and an executive of their firms; the rest were employed executives.

\section{Materials}

The data were collected with semi-structured, in-depth interviews to examine participants' perceptions about vocational graduates' competence requirements and the phenomena affecting those perceptions. The interview questions were created with background theories reflecting the research questions. Altogether ten questions were composed comprising orientation questions and three broad research themes (see Appendix 1): competence demands in the focused organization, the demands of working life from the IVET graduates, and the development of working life competences during the upper-secondary IVET. These themes reflected the actual research questions but they were labelled as written above to better 
illustrate the research questions to the interviewees. A separate form was created to collect background information.

\section{Procedure}

Altogether 14 potential participants were contacted via email and by telephone in September 2016. They were informed about the purpose of the study and asked to volunteer. Ten of them attended. The primary author interviewed participants at their workplaces between September and November 2016. Every participant was first asked for a written consent on a separate form. The length of interviews varied from 45 minutes to two hours. All questions were posed for each participant. If needed, the researcher also asked clarifying questions such as how they justified their arguments and what examples they could give for their arguments.

The first two interviews were pilot interviews. Based on these, firstly, some minor adjustments were made to the framing of three questions. Secondly, the concept of competence was already omitted from the interview questions because it was considered too ambiguous to the interviewees and was replaced by 'readiness'. Although being used as a scientific concept inside the academia, in the Finnish language it is more common to refer to competence with the word 'readiness'. However, being too hard to grasp for the interviewees, an explanation was added to describe that 'readiness' can relate both to domain-specific and more generic knowledge, skills and attitudes (see Appendix 1). The final interview question formulations were used in the remaining eight interviews. Further, as the pilot interviews had only minor difficulties and were otherwise successful, they were included in the research material as well. All ten interviews were recorded and transcribed verbatim, resulting in 166 sheets of transcriptions. 


\section{Analysis}

The data were analysed using qualitative content analysis (QCA) with an abductive approach. QCA was used to create a concise but holistic and valid description of the studied phenomenon, and to create a conceptual categorization (Elo and Kyngäs 2008; Schreier 2012). The abductive approach was chosen to strengthen the validity of this description. Instead of using either induction or deduction as a form of inference (Elo and Kyngäs 2008), these were used successively and iteratively, moving back and forth between data and theory (Timmermans and Tavory 2012). During this iteration, the theoretical background of the study was reframed and broadened so that surprising findings and anomalies could be included in the analysis (Timmermans and Tavory 2012).

In the first phase of the analysis, the first author coded the research material inductively using Atlas.ti 7 software. A unit of analysis was an expression focusing on one idea (Elo and Kyngäs, 2008) which could be a single word, sentence or a combination of sentences. Altogether 646 units were coded. The codes were named descriptively following the ideas of interviewees' expressions. The codes were also allocated under three main dimensions deriving from the research questions (Schreier 2012): competence expectations, recruitment criteria, and employers’ experiences.

In the second, deductive phase the first author pushed the initial codes against the existing theoretical background (see Timmermans and Tavory 2012) which consisted, firstly, of earlier research on upper-secondary IVET and tertiary-education graduate competences, especially from employers’ standpoint (e.g. Gekara and Snell 2018; Kantane et al. 2015; McMurray et al. 2016; Teijeiro et al. 2013; Tynjälä et al. 2016). These studies consider competences as individual characteristics affecting one’s performance (cf. Blömeke, Gustafsson, and Shavelson 2015). Secondly, as the second research question of this study 
addressed employers' recruitment criteria, theoretical background included the aspect of vocational learning as an applicant screening process in which employer organizations observe IVET students conducting their apprenticeships as potential new employees (Pylväs, Nokelainen, and Rintala 2018). Thirdly, to include the view of IVET graduates as fellow employees, theoretical background was also complemented with the theory of Organizational Citizenship Behaviours (OCBs) which describes desirable employee behaviours, especially attitudes, that may contribute to an organization's cohesion and performance (Bolino, Harvey, and Bachrach 2012). As a result, the main dimensions of analysis were maintained but the initial codes under them were merged into larger, consistent categories. Some codes were uncomplicated, articulated quite unanimously by the participants, consonant with the research literature, and thereby easy to merge together. Some codes were more complex to merge. These situations were solved based on research literature.

The following main categories emerged. Domain-specific competence included substantial knowledge, manual skills and profession-related attitudes necessary to conduct professional tasks, for example trade-specific knowledge, assembly techniques and attitudes towards industrial safety matters (e.g Baartman and de Bruijn 2011). Technological competence included IVET students' preliminary technological competences acquired before the studies, for example knowledge of technological concepts, manual dexterity skills and positive attitudes towards technology (Autio 2011). Professional self-perception related to IVET students' evaluation of the self as a professional and as a co-worker (Van Houtte, Demanet, and Stevens 2012). Work-related attitudes included positive employee attitudes supposed to contribute to the cohesion and performance of the workplace (e.g. Bolino, Harvey, and Bachrach 2012; McMurray et al. 2016; Pylväs, Nokelainen, and Rintala 2018). Social competence referred to appropriate, comprehensible and respectful interaction with 
others (Kantane et al. 2015; Tynjälä et al. 2016). Customer service competence involved taking customers' needs into account and delivering high-quality customer service (McMurray et al. 2016). Motivation to work referred to IVET students' and graduates' motivation for the trade and for the job tasks in employer organizations (Kantane et al. 2015; Pylväs, Nokelainen, and Rintala 2018; Teijeiro et al. 2013). Learning competence included both motivation and ability to learn (Kantane et al. 2015; Teijeiro et al. 2013). Job search competence referred to effective performance in job search situations, including writing CVs and cover letters and performing in job interviews (McMurray et al. 2016). Other competences included those competence domains mentioned only a few times, for example ICT skills. Applicant screening referred to apprenticeships as a means for the employer to gradually screen the employability potential of an IVET student (Pylväs, Nokelainen, and Rintala 2018).

Many categories and subcategories emerged under different dimensions as the interviewees addressed the same issues from a different standpoint (i.e. as a competence expectation, recruitment criterion, or employer's experience on a novice worker). Using the same category names enabled the juxtaposition of the main dimensions. The analysis was exclusive: one code could be a part of one category in one main dimension only. Although almost every coding category was based on the theoretical framework of the study, there remained some which were based on the data itself (this is characteristic to QCA; see Schreier [2012, 89]). Three of these were included in the further analysis. First, Hobbies related to goal-oriented free-time activities as a sign of activity and thus as a valuable recruitment criterion. Secondly, Heterogeneity of youth included participants' views on IVET students and graduates as a highly diverse group. Thirdly, Contributions of a novice worker comprised participants' opinions on the benefits of young workers for the professional community. Other 
entirely data-driven categories included interviewees' descriptions of their workplaces and other single, miscellaneous codes that are not relevant for the analysis and will not be addressed here.

In the last phase, categories were further discussed with other researchers and redefined several times. Coding reliability was checked using intercoder reliability (Whitley and Kite 2013, 406). A researcher colleague acquainted with the field of this study analysed $14 \%$ of the randomly selected items from the categories (646 items altogether, 91 used for testing reliability) using the classification schema. There were five differences in coding. Both coders had given the same competence category (and subcategory) to the quotation but had subsumed it under a different main dimension (i.e., competence expectations, recruitment criteria or employers' experiences). In conclusion, the main categories and subcategories are presented with quotation examples in Table 1.

[Table 1 near here]

\section{Results}

All results are presented in Table 2. After the table, the results are reported further in three sections. The first section is devoted to the employers' expectations on graduates' competences. The second section addresses the recruitment criteria. The third section presents employers’ experiences with novice workers.

[Table 2 near here] 


\section{Employers' expectations on IVET graduates' competences}

Domain-specific competence (97 units) was mentioned by all participants. First, they required some fundamental procedural knowledge of the graduates, such as mastering basic tools and assembly techniques of the trade. Second, participants demanded declarative knowledge, awareness of current issues in their trades so that graduates could anticipate future expertise needs. Third, participants expected self-regulative knowledge. Graduates should be able to plan and execute some simple procedures individually and systematically: 'It's about managing the whole process so that you can read the construction drawings and conceive what phases the project includes'. However, none of the participants expected full domainspecific competence of any graduate. In the following, we explain further, domain-general expectations.

All participants mentioned Work-related attitudes (35 units). Four participants discussed Responsibility (10 units), expecting care with the job environment, tools, and cleanliness, as well as a certain level of pro-company thinking that employees show by conscientiously completing their assignments. Five participants raised the issue of Conscientious attendance (8 units). Three of them demanded that employees should restrain from using their mobile phones during working hours. Moreover, five of them highlighted that workers should arrive at work on time. Six participants emphasized Personal initiative (7 units), appreciating novices who contact potential employers themselves, ask for more work and are persistent problem solvers. Three participants reported that a novice worker should have Flexibility (9 units) with working hours, especially, when the job task could be easily finished or there is a tight deadline to meet. One participant pointed out Maintenance of physical health (1 unit), stating that it is paramount in manual work. 
Nine participants addressed Social competence (52 units) in their answers. Seven participants raised the issue of Respect for others (19 units) which comprises various prosocial behaviours such as empathy and friendliness. Good manners were also demanded, for example greeting other people when encountering them, shaking hands and looking into the eyes when having a conversation. Seven of them demanded skilled Communication (17 units): everyone should be able to listen to others, state their opinions and communicate clearly. Six participants highlighted Collaboration (16 units): everyone should get along with other people and be able to work in teams. As an example of this, one participant said: 'Formerly, some craftsmen kept their know-how as a secret so that nobody else could learn it. Today you've got to help others and understand that you don't work alone'.

Six participants demanded Customer service competence (18 units) but added that its demand is interwoven with a worker's job profile. For example, in car sales it is paramount: 'You've got to get close to the customers, understand their needs, use such expressions they understand, and satisfy them. We're aspiring to a lifelong customer relationship'. However, customer service is becoming more important in building maintenance technology as well: 'In a restaurant, waiters are judged by their willingness to be of service, friendliness and manner of speech . . . I highlight to our workers that we're a service business that deals with people. We're judged by the same standards!' At least, customers should be treated in a respectful and polite way and their questions should be answered.

Motivation to work (13 units) was discussed by eight participants. Three of them contended that graduates should pursue a career in the specific industry. Six participants described motivation as an everyday activity, interest and ambition in work which is shown as regular, vigorous and dedicated work. One participant in vehicle technology described 
dedication as follows: 'You can see that the employees are motivated when they're active, ask for advice and check the car thoroughly'.

Learning competence (15 units) was addressed by eight participants. They all mentioned that having Motivation to learn (13 units) is important in general because technical trades and their competence requirements constantly evolve. In particular, novices should be eager to bring up what they do not know because it helps to plan their training and avoid damages: 'If you only think you know, that's wrong. Do not hesitate to ask. . . . Otherwise you may also cause serious damage'. Moreover, two participants mentioned Ability to learn (2 units) as well but they did not clarify or expand upon their answers.

Some Other (7 units) domain-general competences were also mentioned. Three participants discussed foreign language proficiency. English is especially important as the manuals for many tools and software are in English. One participant valued mathematical competence such as basic arithmetic skills and systematic and logical thinking; these skills help to complete daily tasks in technical trades.

In summary, there were three topics which were addressed the most. First, participants expected IVET graduates to show basic domain-specific competence and mastery of simple work procedures. Second, participants required the graduates to have such workrelated attitudes that reflect their positive, responsible and flexible approach to work. Third, participants identified the need for graduates' social competence which is shown as a respectful, communicative and collaborative behaviour towards other people. Next, learning competence, motivation to work and customer service competence drew almost identical attention. Specifically, participants addressed graduate motivation and required both willingness to work in the industry and willingness to learn. Participants recognized customer service competence as an asset in the modern, service-driven working life but added that its 
precise demand is linked to a worker's job profile. Lastly, there were some other expectations, such as the need for foreign language and mathematical skills.

\section{Employer recruitment criteria for IVET students}

All participants described apprenticeships as an Applicant screening process (70 units) and Proven potential (53 units) as a major factor in recruitment decisions: 'We have to see whether the person has a potential for our job environment. A new employee must benefit the workgroup. And if they do, we can hire him or her'. In fact, without performing an apprenticeship, it is difficult for a young person to become employed. Moreover, not everyone even proceeds to a second apprenticeship and may be laid off if lacking potential. Five participants specified that single strengths or weaknesses do not play a large role but the Holistic overview (6 units) of the competence of an applicant does. Four participants added that without the apprenticeship experience, novice job applicants must have some other References (6 units) to show their competence, preferably from other firms or at least they must be acquaintances of a member of staff. Two participants indicated that Success in studies (5 units) is a sign of such already achieved competence.

When asked about competence criteria, participants commonly referred to their previous answers about competence expectations, especially, in terms of domain-specific knowledge, work-related attitudes, social competence and learning competence. In addition, there were some special issues that will be described in the following. First, seven participants emphasized the job applicants' Motivation to work (11 units), their own will to engage in the industry as an ultimate recruitment criterion. As one participant from building maintenance technology said: 'The recruitment of an apprentice depends on their motivation; they have to show that they are sincerely motivated in the trade and that they want to learn the profession'. 
Second, three participants mentioned Job search competence (16 units). While seeking a job, a novice worker should know how to create a CV and a cover letter, how to contact an employer and how to succeed in a job interview. Third, one participant mentioned Hobbies (6 units) because they indicate that a job seeker has a balance between the professional and personal life. Last, two participants discussed Customer service competence (4 units), especially having a positive customer service attitude. For one participant working in car sales, customer service competence was even a paramount recruitment criterion:

If you have two candidates and one is extremely good in customer service by nature and the other is extremely technically oriented, do I have to tell which one gets the job? The former skill is inherent and cannot be learnt and the latter you can, and that's why customer service comes always first!

In summary, participants' competence expectations in recruitment situations were similar to the general competence expectations which were addressed in the former section. Obviously, an IVET graduate applying for a job has to have some job search competence as well to create the job application documents and to perform in the job interview. However, what counts the most, is that the applicant can show her or his motivation to work in the trade and in the specific firm. Most commonly, motivation and other relevant competences are demonstrated in apprenticeships during studies. Thereby, IVET students gradually prove their potential and earn a status of a serious employee candidate.

\section{Employers' experiences with IVET graduates as novice workers}

Domain-specific competence (46 units) was mentioned by all 10 participants. They stated that IVET graduates typically are not ready workers because they lack job experience and understanding of routines. First, they cannot do all assembly tasks on their own (i.e., 
procedural knowledge). Second, they lack knowledge about new technologies, industrial safety matters such as wearing hearing and eye protectors or what factors in their job performance affect their salary (i.e., declarative knowledge). As put by one participant from vehicle technology: 'Our wage structure is online. . . . If you know that keeping up with timetables, showing good behaviour and acquiring professional know-how affects your salary, your first days at work will be a lot easier'. Last, novice workers cannot typically plan and execute work processes on their own, nor they know how their own work is related to the whole (i.e., self-regulative knowledge).

Three participants addressed Technological competence (9 units). They felt that there are fewer students who have practised their technological skills before their studies and have technology-related hobbies: 'Earlier many had been fixing tractors and mopeds with their fathers so that they already had some basic knowledge and could, for instance, change brake pads right away. These modern adolescents concern themselves less with such things'.

Seven participants discussed novice workers’ Professional self-perception (14 units), contending that in the beginning many adolescents worry about if they fit in to the working community and can master their job tasks: 'I can see that they're scared when standing for the first time in my office'. Uncertainty can yield to either overcautious or overeager performance, which may even cause serious safety risks. One participant noted, 'Usually something bad happens if someone is too eager. . . . Either you do first and think afterwards and cause damage or you wear yourself out'.

Work-related attitudes (45 units) were addressed by eight participants. First, four participants discussed Responsibility (13 units), stating that some adolescents have not been careful at work, kept their job environment clean and respected the customers’ property. As put by a participant from vehicle technology: 'It's an important issue what you wear when 
you get into a customer's car so that it won't get dirty'. Two participants stated that the lack of responsibility is something learnt at home, especially in some disadvantaged urban areas. In the more well-off, suburban or rural areas, the social surroundings are better and adolescents learn more responsibility. Second, seven participants brought up the issue of Conscientious attendance (17 units), reporting that in the past novice workers have had problems with adhering to the working hours. They spend excessive amounts of time with mobile phones or do not come to work on time. The modern course-based IVET system exacerbates the latter problem according to one participant:

Formerly, instruction began in the vocational school at eight o'clock and lasted until 15 or 16 in the afternoon. Nowadays, in the course-based system . . . there might be days of only two hours of study. Therefore, the students don't get used to the rhythm of working life.

Third, three participants mentioned that the youth to varying degrees show Personal initiative (5 units) and ask for more work. Fourth, one participant working as a foreman in a large metalwork firm addressed young workers’ Flexibility (5 units). He stated that some young men are reluctant to adjust working times or to do such tasks as tidying up outside of their exact job profile. Lastly, two participants discussed Maintenance of physical health (5 units) and mentioned that some youngsters neither follow a regular circadian rhythm nor sleep enough; consequently, they cannot wake up for work in the morning.

All ten participants addressed Social competence (27 units). Five participants reported that some novice workers, especially apprentices, do not show Respect for others (19 units) by swearing too much or they may 'blurt out inappropriate words in the wrong place' or act otherwise rudely towards workplace mentors or co-workers. One participant in building maintenance technology described this as follows: 'Arrogance is shown as negligence and 
disrespect against the guidance of an older worker. . . . This is not just about swaggering but also belittling or insulting the other person'. Moreover, seven participants reported that novice workers’ Collaboration (8 units) skills with other workers vary considerably.

All ten participants mentioned novice workers’ Motivation to work (28 units). Nine of them mentioned that there have been especially many apprentices but also a few young employees who have not had an 'interest in the industry at all' or they seem to have chosen the trade because of 'feeling compelled to study at least some profession'. However, according to four participants, there have also been those who pursue a career in the industry and are interested in it. As put by a participant working in car sales: 'This job is about will. On the first day of his apprenticeship he said that someday he wants to be our employee. You don’t encounter such people every day!’

Learning competence (30 units) was addressed by nine participants. All of them considered the novice workers’ Motivation to learn (19 units). Especially some apprentices are unwilling to learn either in school or in apprenticeships, lack persistence in studies, and 'do not take their studies seriously'. However, there are also those who '. . . have had an interest already at school and have been willing to learn in apprenticeship with us as well'. Moreover, seven participants noted novice workers’ Ability to learn (11 units), mentioning that some graduates have had learning difficulties and have not acquired enough knowledge and skills during their studies, while some have shown quick learning. As put by one participant: 'They may learn the right procedures at once because they do not have to first get rid of the old ones'.

Five participants discussed Other (10 units) domain-general competences. Three participants acknowledged novice workers' skills in English. Further, three participants recognized that the youth comprehend information technology more easily than the older 
workers. One participant from electrical engineering mentioned that novice workers have even coached their co-workers: 'We have implemented an electronic time card system. Older workers cannot comprehend it well but the younger ones have taught them to use it!'

Besides experiences of competence, participants also thought about novice workers in general. Everyone mentioned that the young are very Heterogeneous (24 units) when they first enter the workplace either as an apprentice or as a recently employed worker: 'Young graduates are unlike. Some are more skilled than others, it's just a fact'. They also indicated that not every student graduates because of changing the study programme or aborting the studies for other reasons. However, students mature during their studies and show better levels of competence towards the end of their studies.

Furthermore, the participants were asked about what novice workers bring with them to their workplaces (see Appendix 1). We subsumed their answers into the category of the Contribution of a novice worker (34 units). Participants felt that novice workers enliven the atmosphere and motivate older workers because they have lots of vigour. They also appreciated novice workers' different views: 'For us [older workers], it’s so easy to stick with old customs but these juniors may question many things with their views and "wake us up" to think in a new way’. Lastly, participants stated that novice workers enable the continuity of business by giving their input of labour, learning the profession and replacing retiring workers.

In summary, participants stated that IVET graduates are very heterogeneous in terms of their competences. Usually, they are not fully ready as workers. They show modest domain-specific competence and cannot perform as effectively as their older co-workers. However, the participants considered these shortcomings obvious due to the lack of job experience and routines. Further, graduates may have a weaker professional self-perception 
which may occur as overcautious or overeager working. As regards social competence, especially some apprentices had acted disrespectfully towards others. Moreover, participants pointed out that the young differ heavily regarding their motivation to work and motivation to learn. Work-related attitudes are problematic for some young graduates as well, especially responsibility at work and conscientious attendance. Last, despite the problems there have been with some graduates, there are also those who contribute to the success of their workplaces, and are thereby valued as junior colleagues.

\section{Discussion}

\section{Methodological reflections}

The validity of qualitative research is based on the accountability and visibility of the research process (Anfara, Brown, and Mangione 2002). The research questions of this study were based on a rigorous study of earlier research to determine what needed to be known (Anfara, Brown, and Mangione 2002). The research participants had broad experience from apprenticeship cooperation with the VET provider to make sure that the most adequate research material available would be collected and demonstrate the link between the data and the results (Anfara, Brown, and Mangione 2002; Elo and Kyngäs 2008). Moreover, this study commits to the ethical principles of research set by the university the researchers are affiliated to. Participation to the study was voluntary and participants were asked for a written consent. Their anonymity was also guaranteed through the research process. Research results were reported in as unambiguous way as possible.

The study was limited to the vocational fields of technology, transport and natural sciences to keep it manageable. Despite this limitation, its results may be generalized to other vocational fields to some extent because earlier research suggests that different 
employers think in a quite unambiguous way about domain-general competence expectations (Teijeiro et al. 2013). However, the results concerning participants' experiences on novice workers relate only to their own apprentices and newcomer employees. Therefore, these results can mainly be associated with other students and graduates in the above-mentioned vocational fields; generalizations to other vocational fields should be made with caution. Moreover, due to the chosen in-depth viewpoint in this study, only employers' expectations were addressed. This viewpoint was reasonable as employers make the final recruitment and hiring decisions (Teijeiro et al. 2013). Still, the results might have had other nuances if more viewpoints had been involved. These call for further research.

\section{Results in the light of the previous literature}

Competence expectations. Consonant with earlier research (in tertiary education; e.g., Tymon [2013]), we found that a novice worker does not have to be fully professionally competent but should have the potential to develop. Professional mastery takes several years of work experience to refine and maintain (as also suggested by Billett [2014]). Once achieved, it is highly valued and needed. As put by one participant in electrical engineering: 'Everything has become more technical, for instance, documentation has got digitalized . . . However, the actual work we do won't cease to exist. Robots may emerge but they may be extremely difficult to program'. Thus, every technical job cannot be easily automated, at least those requiring fast-pace application of high-quality assembly expertise.

Our findings from the viewpoint of practitioner-level employers clearly indicated that this potential for professional mastery is based on fundamental domain-specific expertise of the trade, such as mastery of basic tools and assembly techniques; awareness of current issues and an ability to plan, execute and assess simple work procedures. In earlier 
research, some scholars (e.g. Teijeiro et al. 2013; McMurray et al. 2016; Pylväs, Nokelainen, and Rintala 2018) consider domain-specific competence subsidiary to domain-general competences in recruitment situations. Some others point out that domain-general competences are not usually enough to perform in a certain profession (Gekara and Snell 2018). Our results uniquely showed that domain-general competences seem to make the difference only if a graduate jobseeker can first prove her or his domain-specific potential. Consequently, domain-specific competence should stay at the core of vocational education.

The findings further imply that employers do expect domain-general competences as well. Within these expectations, motivational and attitudinal as well as social factors play significant roles (as also found by Ferm et al. [2018]; Jackson [2015]; Kantane et al. [2015]; Pylväs, Nokelainen, and Rintala [2018]). First, as the modern world of work constantly evolves, every young worker must keep up with the change by being motivated both for the industry and to develop one's competences. Second, everyone should have workrelated attitudes, such as keeping up with the working hours, using work time only for work, being responsible and taking initiative. Third, everyone needs social competence which is shown as a respectful, appropriate and communicative behaviour towards others, including customers and other stakeholders.

Our findings on domain-general competences were visibly in line with some earlier studies suggesting that attitudes and social competence are considered to improve social cohesion and trust among individuals (Bolino, Harvey, and Bachrach 2012; Ferm et al. 2018; Pylväs, Nokelainen, and Rintala 2018). Some scholars have labelled attitudes as OCBs, emphasizing the trust they create between employees at the workplace (Bolino, Harvey, and Bachrach 2012). Similarly, attitudes and social skills have been considered as a means for IVET apprentices to access the professional community and adopt its identity (see Ferm et al. 
2018; Nägele and Stalder 2016; Pylväs, Nokelainen, and Rintala 2018). Our results confirmed these insights and contribute to the discussion by emphasizing that the modern business environment seems to be service-oriented even in manual-labour-oriented technical trades. Employees' attitudes and social competence contribute to companies' public image. Consequently, it is not enough that apprentices learn to act in their professional communities, they also need to learn to consider how their behaviour is regarded by customers. As the development of trust seems to be intervowen with right attitudes and efficient human interaction, we suggest that attitudes and social competence should be emphasized already in school and recommend further research on their acquisition and development during vocational studies.

In this study, young graduates’ competences were focused on. Keeping this in mind, interestingly, the participants considered the above-mentioned domain-general competences essential. More academic competences such as language proficiency, mathematical thinking and ICT skills received only minor attention although they have been heavily addressed in the policy papers on adult skills (European Council and European Commission 2010; OECD 2016). Consequently, it should be further studied to what extent highly academic competences are relevant for technical vocational graduates.

Recruitment criteria. Employers expect the same competences in recruitment as they do in the everyday work. However, a graduate job applicant should have proved to possess them, commonly in an apprenticeship (see Pylväs, Nokelainen, and Rintala 2018). Job search competence promotes success in recruitment, for example giving a positive impression in a job interview (see McMurray et al. 2016) and above all, convincing the employer of one’s work motivation. 
Employers' experiences. Our findings clearly indicated that IVET graduates are not usually ready professionals and fall behind with domain-specific competence. Employers consider this obvious because novices do not yet have broad job experience. Our findings further suggested that many adolescents also lack sufficient domain-general competences. First, according to the participants many are not motivated to study or work. Employers take apprentices to screen potential future employees (see Pylväs, Nokelainen, and Rintala 2018) and might not be willing to offer subsequent apprenticeships to the unmotivated. Second, the participants reported on challenges with novice workers' work-related attitudes. Many are not used to keep up with the working hours and timetable, and some do not show responsibility for their tasks (as also found by Pylväs, Nokelainen, and Rintala [2018] regarding students in social and health care services). Third, the participants mentioned that some adolescents have shown disrespect towards the co-workers and arrogance towards their instruction. Irresponsible and disrespectful adolescents hardly earn the trust of their working communities and face a risk to be permanently laid off as lacking potential (see Ferm et al. 2018).

The above-mentioned findings especially signify that the participants recognized severe problems regarding the motivation to work, motivation to learn, work-related attitudes and social competence of some technical IVET graduates. We believe that there might be a structural problem related to these above-mentioned problems. For a modern adolescent it is hard to get a summer job before the upper-secondary-level studies or a side job along the studies either due to the economic situation in the society or because in many technical professions a formal qualification is required of safety reasons or by authorities (e.g. electrician). Without job experience the youth cannot assimilate into the requirements of working life or develop an initial motivation for the study. However, this assumption calls for further research. 
Our findings also underlined that the youth are a heterogeneous group: some have great weaknesses with several competences, few have a profound understanding and many others lie in between. Besides, adolescents are usually concerned about how they fit into the working community or about their inadequate expertise (as also found by Jackson [2015] in tertiary education). Social and instructional support may help students to overcome these difficulties and promote their self-perception, motivation and success (Ferm et al. 2018; Jackson 2015). Thus, we suggest further studies on the role of teachers and supportive instructional structures in school and at workplace.

Finally, our findings suggest that the youth are vital for the continuity of industry and enterprises. Not only do they contribute by giving their own input of labour (cf. Pylväs, Nokelainen, and Rintala 2018) but also by giving new insights and motivating older workers with their enthusiasm. These findings add to the discussion of vocational identity (see Ferm et al. 2018), suggesting that the youth not only adopt a ready professional identity but also shape it and enrich it as soon as they have gained membership in the professional community.

\section{Conclusion}

This study has added to the theoretical discussion about upper-secondary IVET graduates' working life competences by providing an in-depth view to the scarcely addressed standpoint of practitioner-level employers (see Billett 2014; Pylväs, Nokelainen, and Rintala 2018). Our results emphasized that fundamental domain-specific competence forms the base for technical-trade IVET graduate competence needs along with such domain-general competences as motivation to work, positive work-related attitudes, learning competence and 
social competence which enable the integration of the youth into their professional communities.

However, the discussion about necessary working life competences comprises various, even controversial, nuances (Blömeke, Gustafsson, and Shavelson 2015; Jackson 2015). There is a risk that the youth become anxious about lacking some quality which is too vague to conceive or to attain (Jackson 2015). Since competences smoothen the integration of the youth into the job market (Jackson 2015), it is important that students receive clear and concise information and training about competences. To better understand the multi-faceted phenomenon of working life competences, other stakeholders' viewpoints should be studied and involved as well, for instance the opinions of IVET teachers and students (Mulder 2016; Nylund et al. 2018). Still, the results of this study can be utilized to elucidate employer concerns when instruction and educational policies are developed so that students would be better prepared to adapt and act in modern working life.

\section{Declaration of interest statement}

No potential conflict of interest was reported by the authors. 


\section{References}

Anfara Jr, V.A., K.M. Brown, and T.L. Mangione. 2002. “Qualitative analysis on stage: Making the research process more public.” Educational Researcher 31 (7): 28-38. doi:10.3102/0013189X031007028.

Autio, O. 2011. “The Development of Technological Competence from Adolescence to Adulthood.” Journal of Technology Education $22 \quad$ (2): 71-89. doi:10.21061/jte.v22i2.a.5.

Baartman, L., and E. de Bruijn. 2011. "Integrating knowledge, skills and attitudes: Conceptualising learning processes towards vocational competence.” Educational Research Review 6: 125-134. doi:10.1016/j.edurev.2011.03.001.

Billett, S. 2014. "The standing of vocational education: sources of its societal esteem and implications for its enactment.” Journal of Vocational Education \& Training 66 (1): 121. doi:10.1080/13636820.2013.867525.

Blömeke, S., J. Gustafsson, and R.J. Shavelson. 2015. “Beyond dichotomies. Competence viewed as a continuum.” Zeitschrift für Psychologie 223 (1): 3-13. doi:10.1027/21512604/a000194. 
Bolino, M.C., J. Harvey, and D.G. Bachrach. 2012. "A self-regulation approach to understanding citizenship behavior in organizations.” Organizational Behavior and Human Decision Processes 119 (1): 126-139. doi:10.1016/j.obhdp.2012.05.006.

Cedefop ReferNet Finland. (2016). Finland VET in Europe - Country Report, 2016. Retrieved January 24, 2019 from: https://cumulus.cedefop.europa.eu/files/vetelib/2016/ 2016_CR_FI.pdf

Elo, S., and H. Kyngäs. 2008. "The qualitative content analysis process.” Journal of Advanced Nursing 62 (1): 107-115. doi:10.1111/j.1365-2648.2007.04569.x.

European Council and European Commission. 2010. “2010 joint progress report of the council and the commission on the implementation of the 'education and training 2010 work programme’”. Official Journal of the European Union, C, 117. Retrieved June 26, 2015 from http://eur-lex.europa.eu/LexUriServ/LexUriServ.do?uri=OJ:C:2010:117: 0001:0007:EN:PDF.

Evers, A. T., and B. I. Van der Hejden. 2017. “Competence and professional expertise” In Competence-Based Vocational and Professional Education: Bridging the Worlds of Work and Education, edited by M. Mulder, 38-101. Cham: Springer. Accessed 18 January 2019. ProQuest Ebook Central.

Ferm, L., D. P. Thunqvist, L. Svensson, and M. Gustavsson. 2018. “Students' strategies for learning identities as industrial workers in a Swedish upper secondary school VET 
programme." Journal of Vocational Education \& Training 70 (1): 66-84. doi:10.1080/13636820.2017.1394357.

Gekara, V., and D. Snell. 2018. "Designing and delivering skills transferability and employment mobility: the challenges of a market-driven vocational education and training system.” Journal of Vocational Education \& Training 70 (1): 107-129. doi:10.1080/13636820.2017.1392996.

Ilomäki, L., S. Paavola, M. Lakkala, and A. Kantosalo. 2016. "Digital competence - an emergent boundary concept for policy and educational research.” Education and Information Technologies 21 (3): 655-679. doi:10.1007/s10639-014-9346-4.

Jackson, D. 2015. “Employability skill development in work-integrated learning: Barriers and best practice." Studies in Higher Education $40 \quad$ (2): 350-367. doi:10.1080/03075079.2013.842221.

Kantane, I., B. Sloka, I. Buligina, G. Tora, R. Busevica, A. Buligina, J. Dzelme, and P. Tora. 2015. "Expectations by Employers on Skills, Knowledge and Attitudes of Employees." European Integration Studies 9: 224-234. doi:10.5755/j01.eis.0.9.12809.

McMurray, S., M. Dutton, R. McQuaid, and A. Richard. 2016. "Employer demands from business graduates.” Education+Training 58 (1): 112-132. doi:10.1108/ET-02-20140017. 
Mulder, M. 2016. Competence and the Alignment of Education and Work. In CompetenceBased Vocational and Professional Education: Bridging the Worlds of Work and Education, edited by Martin Mulder, 229-251. Cham: Springer. Accessed January 18, 2019. ProQuest Ebook Central.

Nägele, C., and B. E. Stalder. 2016. Competence and the Need for Transferable Skills. In Competence-Based Vocational and Professional Education: Bridging the Worlds of Work and Education, edited by Martin Mulder, 739-753. Cham: Springer. Accessed January 18, 2019. ProQuest Ebook Central.

Nylund, M, P.-Å. Rosvall, E. Eiríksdóttir, A.-S. Holm, U. Isopahkala-Bouret, A.-M. Niemi, and G. Ragnarsdóttir. 2018. "The Academic-vocational Divide in Three Nordic Countries: Implications for Social Class and Gender." Education Inquiry 9 (1): 97-121. doi:10.1080/20004508.2018.1424490.

OECD. 2016. Skills matter: further results from the survey of adult skills. Paris: OECD Skills Studies, OECD Publishing. doi: 10.1787/9789264258051-en

Pylväs, L., P. Nokelainen, and H. Rintala. 2018. ”Finnish Apprenticeship Training Stakeholders' Perceptions of Vocational Expertise and Experiences of Workplace Learning and Guidance.” Vocations and Learning 11: 223-243. doi:10.1007/s12186017-9189-4.

Schreier, M. 2012. Qualitative content analysis in practice. London: Sage. 
Teijeiro, M., P. Rungo, and J. Freire. 2013. “Graduate competencies and employability: The impact of matching firms’ needs and personal attainments.” Economics of Education Review 34: 286-295. doi:10.1016/j.econedurev.2013.01.003.

Timmermans, S., and I. Tavory. 2012. “Theory construction in qualitative research: From grounded theory to abductive analysis.” Sociological Theory 30 (3): 167-186. doi:10.1177/0735275112457914.

Toom, A. 2012. “Considering the artistry and epistemology of tacit knowledge and knowing.” Educational Theory 62 (6): 621-640. doi:10.1111/edth.12001.

Tymon, A. 2013. “The student perspective on employability.” Studies in Higher Education 38 (6): 841-856. doi:10.1080/03075079.2011.604408.

Tynjälä, P. 2008. “Perspectives into learning at the workplace.” Educational Research Review 3 (2): 130-154. doi:10.1016/j.edurev.2007.12.001.

Tynjälä, P., A. Virtanen, U. Klemola, E. Kostiainen, and H. Rasku-Puttonen. 2016. ”Developing social competence and other generic skills in teacher education: Applying the model of integrative pedagogy.” European Journal of Teacher Education 39 (3): 368-387. doi:10.1080/02619768.2016.1171314. 
Van Houtte, M., J. Demanet, and P. A. Stevens. 2012. Self-esteem of academic and vocational students: Does within-school tracking sharpen the difference? Acta Sociologica 55 (1): 73-89. doi:10.1177/0001699311431595.

Van Tartwijk, J., R. Zwart, and T. Wubbels. 2017. Developing Teachers’ Competences with the Focus on Adaptive Expertise in Teaching. In The SAGE Handbook of Research on Teacher Education, edited by Jean D. Clandinin and Jukka Husu, 820-835. London: SAGE Publications. Accessed January 18, 2019. ProQuest Ebook Central.

Whitley, B.E., and M.E. Kite. 2013. The principles of research in behavioural science. 3rd ed. New York, NY: Routledge. 


\section{Appendix 1. Interview question frame.}

\section{Competence demands in the focused organization}

1. Describe your business and products.

2. How are you dealing with young employees in your work?

3. What kind of competence is needed in the assignments of your firm?

\section{The demands of working life from the VET graduates}

'In this study, we focus on VET graduates' readiness to enter the working life. On the one hand, readiness can relate to professional, job-specific knowledge, skills and attitudes; on the other hand, it can relate to more general knowledge, skills and attitudes of a good worker. For example, a good secretary, a cleaner and a car sales assistant certainly share some qualities which make them good workers.'

4. What qualities comprise the readiness of VET graduates. Why are those important?

5. From the qualities you mentioned which are most important when hiring a young person?

6. What challenges have you had with young workers?

\section{The development of working life competences during the upper-secondary VET}

7. In your opinion, what knowledge, skills and attitudes, needed in the working life, the recently employed vocational graduates master well?

8. What is vocational graduates' contribution to the working life?

9. On the other hand, what knowledge, skills and attitudes, needed in the working life, the recently employed vocational graduates are not mastering well?

10. Is there anything else you would like to say? 
Table 1. Categories and subcategories of analysis

\author{
Category name Example \\ Subcategories \\ (if any)
}

\title{
Competences
}

Domain-specific competence

You should know how to make pipe joints.

\section{Technological competence}

Professional selfperception

\section{Work-related attitudes}

Responsibility

Conscientious attendance

Personal initiative

Flexibility

Maintenance of physical health

\section{Social competence}

Respect for others

Communication

Collaboration

Customer service competence

Motivation to work

\section{Learning competence}

Motivation to learn

Ability to learn

Job search competence
It's a good starting point [for manual work] if applicants can fix their own bikes and mopeds.

In the beginning, working is very cautious...They wonder if they really can do it.

Cleaning up the work mess. When workers assemble a switch, they don't leave little chord pieces on the floor.

Co-workers get quickly angry if others just keep sending messages or browse Facebook.

I think it's positive that adolescents themselves call and ask for a job.

We demand some flexibility so that they won't stop working and go home before the work is done.

It's ridiculous but true. Even this summer one of the newest employees quit because he couldn't wake up for work in the morning.

Arrogance means not listening to or respecting an older co-worker.

When dealing with a customer, a worker shouldn't use any automotive jargon but speak in a comprehensible way about what faults were found and what was done to correct them.

...getting along with different people. This is necessary in every job.

Nowadays no car or spare part should remain unsold because of poor customer service.

Somehow, I feel that they [graduates] have wanted to come here to work and that they have not been compelled to do so.

If an applicant has enough will, he or she will learn very quickly.

...but applicants should also be capable to learn.

When reviewing resumes, we get a better picture of the applicants, when they use the correct language. 
Other competences Competence domains that were not included in the above-mentioned categories and gained only a few comments included ICT skills, language proficiency, mathematical skills

\section{Other issues}

\section{Applicant screening}

Proven potential Some apprentices won't get another chance when we see that they are in the wrong trade.

Holistic

overview

The hiring decision is about getting an overall picture of the competence of an

References

Success in studies applicant.

We don't hire an unknown person easily. At least there must be someone in the organisation who knows the applicant and what (s)he's about.

*Hobbies

In hobbies a person can always find and learn some general life skills.

*Heterogeneity of Some of the graduates are so ready for work while some are not. youth

*Contributions of a novice worker

If we do not hire younger employees, we will have problems when the older ones retire.

Note. ${ }^{*}$ An entirely data-driven category 
Table 2. Frequencies of categories

\begin{tabular}{|c|c|c|c|c|c|c|}
\hline & \multicolumn{2}{|c|}{ RQ1. Expectations } & \multicolumn{2}{|c|}{ RQ2. Recruitment } & \multicolumn{2}{|c|}{ RQ3. Experiences } \\
\hline Competences & $\%$ & $(\mathbf{f} / \mathrm{N})$ & $\%$ & $(\mathbf{f} / \mathrm{N})$ & $\%$ & $(\mathbf{f} / \mathbf{N})$ \\
\hline Domain-specific competence & 41 & $(97 / 10)$ & 11 & $(16 / 4)$ & 17 & $(46 / 10)$ \\
\hline Technological competence & - & - & - & - & 3 & $(9 / 3)$ \\
\hline Professional self-perception & - & - & - & - & 5 & $(14 / 7)$ \\
\hline Work-related attitudes & 14 & $(35 / 10)$ & 6 & $(8 / 4)$ & 17 & $(45 / 8)$ \\
\hline Responsibility & 4 & $(10 / 4)$ & - & - & 5 & $(13 / 4)$ \\
\hline Conscientious attendance & 3 & $(8 / 5)$ & 1 & $(2 / 2)$ & 6 & $(17 / 7)$ \\
\hline Personal initiative & 3 & $(7 / 6)$ & 4 & $(5 / 3)$ & 2 & $(5 / 3)$ \\
\hline Flexibility & 4 & $(9 / 3)$ & 1 & $(1 / 1)$ & 2 & $(5 / 1)$ \\
\hline Maintenance of physical health & 0 & $(1 / 1)$ & - & - & 2 & $(5 / 2)$ \\
\hline Social competence & 22 & $(52 / 9)$ & 4 & $(5 / 4)$ & 10 & $(27 / 10)$ \\
\hline Respect for others & 8 & $(19 / 7)$ & 4 & $(5 / 4)$ & 7 & $(19 / 5)$ \\
\hline Communication & 7 & $(17 / 7)$ & - & - & - & - \\
\hline Collaboration & 7 & $(16 / 6)$ & - & - & 3 & $(8 / 7)$ \\
\hline Customer service competence & 8 & $(18 / 6)$ & 3 & $(4 / 2)$ & - & - \\
\hline Motivation to work & 5 & $(13 / 8)$ & 8 & $(11 / 7)$ & 10 & $(28 / 10)$ \\
\hline Learning competence & 7 & $(15 / 8)$ & 4 & $(6 / 4)$ & 11 & $(30 / 9)$ \\
\hline Motivation to learn & 5 & $(13 / 8)$ & 4 & $(6 / 4)$ & 7 & $(19 / 9)$ \\
\hline Ability to learn & 1 & $(2 / 2)$ & - & - & 4 & $(11 / 7)$ \\
\hline Job search competence & - & - & 11 & $(16 / 3)$ & - & - \\
\hline Other competences & 3 & $(7 / 4)$ & - & - & 4 & $(10 / 5)$ \\
\hline \multicolumn{7}{|l|}{ Other issues } \\
\hline Applicant screening & - & - & 49 & $(70 / 10)$ & - & - \\
\hline Proven potential & - & - & 37 & $(53 / 10)$ & - & - \\
\hline Holistic overview & - & - & 4 & $(6 / 5)$ & - & - \\
\hline References & - & - & 4 & $(6 / 4)$ & - & - \\
\hline Success in studies & - & - & 4 & $(5 / 2)$ & - & - \\
\hline Hobbies & - & - & 4 & $(6 / 1)$ & - & - \\
\hline Heterogeneity of the youth & - & - & - & - & 9 & $(24 / 10)$ \\
\hline Contribution of a novice worker & - & - & - & - & 13 & $(34 / 10)$ \\
\hline TOTAL & 100.00 & (237) & 100.00 & (142) & 100.00 & (267) \\
\hline
\end{tabular}

Note. $\mathrm{F}=$ frequency of analysis units. $\mathrm{N}=$ number of participants raising the issue (max. 10). - = data not obtained 